\title{
A SOCIALIZAÇÃO DA RIQUEZA INTELECTUAL PSICOLOGIA, MARXISMO E PEDAGOGIA
}

\author{
entrevista com NEWTON DUARTE*
}

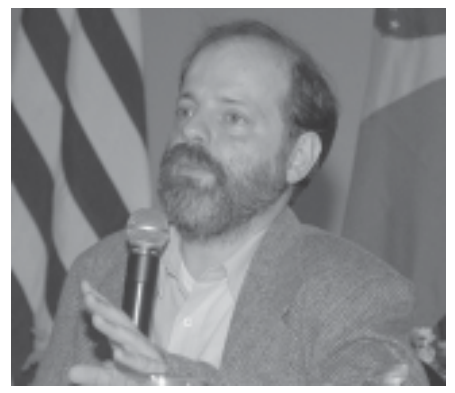

Ele esteve em Botucatu em fevereiro de 2007.

Durante as Oficinas de Estudos Pedagógicos da Unesp, coordenadas pela Pró-Reitoria de Graduação, ministrou a palestra A construção do conhecimento no processo ensino-aprendizagem, expondo suas idéias e contribuindo para o debate sobre a pedagogia e o papel do educador no ensino superior. Ali nasceu o convite para esta entrevista, agora compartilhada com os leitores da Interface. Antes, um breve perfil do entrevistado...

\section{A formação e vida profissional}

Pedagogo pela Universidade Federal de São Carlos, Newton Duarte é docente da Unesp desde 1988. Atualmente é livre-docente em Psicologia da Educação no campus de Araraquara. Bolsista de produtividade em pesquisa do CNPq desde 1993, de agosto de 2003 a junho de 2004 realizou pós-doutorado na Universidade de Toronto, Canadá. Em 2002 criou o grupo de pesquisa Estudos Marxistas em Educação, que hoje conta com pesquisadores da Unesp, UFSCar, UFSC, UFPR, UFES, UEM e UESC. No biênio 2006-2007 coordena o GT Filosofia da Educação da Associação Nacional de Pós-Graduação em Educação (ANPED).

\begin{abstract}
A produção
Newton Duarte tem extensa produção publicada no exterior e no Brasil, da qual destacam-se os livros: A individualidade para-si (1993), Educação escolar, teoria do cotidiano e a escola de Vigotski (1996), Vigotski e o aprender a aprender: crítica às apropriações neoliberais e pósmodernas da teoria vigotskiana (2000) e Sociedade do conhecimento ou sociedade das ilusões? (2003). Também organizou as coletâneas Sobre o construtivismo (2000) e Crítica ao fetichismo da individualidade (2004). Em 2006 o livro Critical perspectives on activity: explorations across education, work and everyday life, organizado por ele, Peter Sawchuk e Mohamed Elhammoumi foi publicado pela editora da Universidade de Cambridge.
\end{abstract}

\begin{abstract}
A pedagogia marxista
Desde 1993 Newton Duarte desenvolve e coordena projetos de pesquisas cuja produção de reflexões e conhecimentos tem como temas centrais: o papel da educação escolar na formação do indivíduo; elementos para uma teoria histórico-crítica do trabalho educativo; o construtivismo: suas muitas faces, filiações e interfaces com outros modismos e, atualmente, a Teoria da atividade e a Educação na sociedade contemporânea. Crítico radical aos ideários pedagógicos do universo ideológico neoliberal e pós-moderno, explicita suas posições sobre a educação e a psicologia da educação, defendendo a pedagogia marxista. Em "Vigotski e o 'aprender a aprender': crítica às apropriações neoliberais e pós-modernas da teoria vigotskiana", Duarte polemiza com uma tendência muito comum entre educadores brasileiros nos dias atuais: a de se propor aproximações entre as concepções de Vigotski e as de ideários com o lema "aprender a aprender", descaracterizando as raízes marxistas do pensador russo.
\end{abstract}

Colaboraram: Sueli Terezinha Ferreira Martins, Miriam Celí Pimentel Porto Foresti, Mariangela Scaglione Quarentei e Adriana Ribeiro, do Corpo Editorial de Interface. 
o que nos levou até o professor foi a sua tese de que há uma psicologia objetivamente contida nos conteúdos escolares e que a psicologia da educação deveria incluir esses conteúdos entre seus objetos de estudo e pesquisa. Em que idéias, teorias, pressupostos, esta tese se ancora?

O ponto de partida para minha reflexão foi meu trabalho como professor $e$ pesquisador na área de psicologia da educação e meus estudos na perspectiva da construção de uma pedagogia marxista. Durante todo o século $\mathrm{XX}$, quando a psicologia tomou a educação escolar como objeto de estudos e pesquisas, o ensino dos conteúdos escolares quase sempre permaneceu como um tema bastante marginal, quando não totalmente excluído do rol de temas abordados pela psicologia da educação. Essa afirmação deve, entretanto, ser relativizada considerando-se que, a rigor, a psicologia não é uma ciência unificada, estando dividida em correntes não apenas distintas como também conflitantes umas com as outras. A definição do próprio objeto da psicologia pode mudar segundo a abordagem teórica adotada. No caso da psicologia da educação, a situação não poderia ser diferente, ou seja: a depender da perspectiva teórica pode-se incluir ou não os conteúdos escolares, seu ensino e sua aprendizagem entre os objetos de estudo e pesquisa. Uma psicologia da educação de fundamentação teórica marxista deve necessariamente incluir entre seus principais objetos de estudo e pesquisa a psicologia humana objetivada nesses conteúdos. O marxismo, ao contrário do que afirma o senso comum acadêmico, dominado pelas idéias de cunho liberal e pós-moderno, possui um grande potencial, ainda pouco explorado, no tocante à compreensão da psicologia humana.

\section{Isso quer dizer...}

Que é muito comum ouvirmos a afirmação de que o marxismo relegaria a um segundo plano, ou até mesmo desconsideraria inteiramente, a individualidade e a subjetividade em prol de uma concepção de mundo na qual haveria espaço apenas para o coletivo e para as determinações materiais da vida humana. Essa afirmação revela, no mínimo, total ignorância dos textos clássicos do marxismo. A dialética entre objetividade e subjetividade sempre esteve presente na obra de Marx. Qualquer pessoa que, despida de preconceitos, leia o que Marx escreveu em obras como Os Manuscritos Econômico-Filosófico de 1844 (Manuscritos de Paris), A Ideologia Alemã, ou Elementos Fundamentais Para a Crítica da Economia Política (Grundrisse: 1857-1858) chegará à conclusão que a visão de história social preconizada por ele reserva lugar de destaque para o desenvolvimento histórico da individualidade humana. Claro que isso não significa afirmar que todos deverão concordar com a concepção marxiana de individualidade e de seu desenvolvimento histórico, mas já não poderão justificar a defesa da visão liberal-burguesa ou da visão pós-moderna em nome de uma suposta desconsideração da individualidade e da subjetividade por parte do marxismo. 


\section{O professor defende, então, a idéia de que há lugar no marxismo para as discussões sobre individualidade e subjetividade?}

Não pretendo adotar uma atitude defensiva neste espaço de reflexão. O que afirmo é que abordagem marxista está além de qualquer outra, no que se refere aos estudos sobre o indivíduo e a subjetividade. Idéias descritas por Marx no século XIX, ou Vigotsky, no início do século XX, preservam todo seu vigor e mostram-se muito avante de milhares de páginas que foram escritas durante todo o século XX (e neste início de século XXI), por correntes idealistas da filosofia, psicologia, das ciências sociais e da educação. Um exemplo, que trago para nossa reflexão, é a seguinte passagem dos Manuscritos Econômico-Filosóficos escritos por Marx em 1844:

(...) assim como a música desperta primeiramente o sentido musical do homem, assim como para o ouvido não musical a mais bela música não tem nenhum sentido, é nenhum objeto, porque o meu objeto só pode ser a confirmação de uma das minhas forças essenciais, portanto só pode ser para mim da maneira como a minha força essencial é para si como capacidade subjetiva, porque o sentido de um objeto para mim (só tem sentido para um sentido que lhe corresponda), vai precisamente tão longe quanto vai o meu sentido, por causa disso é que os sentidos do homem social são sentidos outros que não os do não social; [é] apenas pela riqueza objetivamente desdobrada da essência humana que a riqueza da sensibilidade humana subjetiva, que um ouvido musical, um olho para a beleza da forma, em suma as fruições humanas todas se tornam sentidos capazes, sentidos que se confirmam como forças essenciais humanas, em parte recém cultivados, em parte recém engendrados. Porém não só os cinco sentidos, mas também os assim chamados sentidos espirituais, os sentidos práticos (amor, vontade etc.), numa palavra o sentido humano, a humanidade dos sentidos, vem a ser primeiramente pela existência do seu objeto, pela natureza humanizada. A formação dos cinco sentidos é um trabalho de toda a história do mundo até aqui. (p.110)

Mesmo quem não esteja familiarizado com a obra de Marx não poderá deixar de reconhecer como é rica a maneira pela qual o filósofo alemão abordou o tema das relações entre objetividade e subjetividade. E essa riqueza ainda está por ser explorada em toda sua plenitude pelas diversas áreas do conhecimento. Eu me pergunto: como o estudo da subjetividade humana poderá avançar de forma efetiva, poderá superar os impasses e os becos sem saída nos quais tem desembocado, sem adotar essa abordagem sugerida por Marx, ou seja, a análise da subjetividade humana contida nas obras objetivas resultantes da prática histórica da humanidade? Há toda uma riqueza psicológica nos frutos do trabalho humano, mas boa parte dos estudos em psicologia e em educação tem ignorado essa riqueza psicológica objetivamente existente. 


\section{Sabemos que essa riqueza psicológica objetivamente existente foi foco dos estudos de Vigotski e seus seguidores...}

Realmente! Sobre as relações dialéticas entre objetivo e subjetivo e entre social e individual no campo da fruição das obras de artes pelos indivíduos, Vigotski, em seu livro Psicologia da Arte (1998, p.315), escreveu as seguintes palavras (que também socializo neste espaço):

É muito ingênuo interpretar o social apenas como coletivo, como existência de uma multiplicidade de pessoas. O social existe até onde há apenas um homem $e$ as suas emoções pessoais. Por isso, quando a arte realiza a catarse $e$ arrasta para esse fogo purificador as comoções mais íntimas e mais vitalmente importantes de uma alma individual, o seu efeito é um efeito social. A questão não se dá da maneira como representa a teoria do contágio, segundo a qual o sentimento que nasce em um indivíduo contagia a todos, torna-se social; ocorre exatamente o contrário. A refundição das emoções fora de nós realiza-se por força de um sentimento social que foi objetivado, levado para fora de nós, materializado e fixado nos objetos externos da arte, que se tornaram instrumento da sociedade. A peculiaridade essencialíssima do homem, diferentemente do animal, consiste em que ele introduz e separa do seu corpo tanto o dispositivo da técnica quanto o dispositivo do conhecimento científico, que se tornam instrumentos da sociedade. De igual maneira, a arte é uma técnica social do sentimento, um instrumento da sociedade através do qual incorpora ao ciclo da vida social os aspectos mais íntimos e pessoais do nosso ser. Seria mais correto dizer que o sentimento não se torna social mas, ao contrário, torna-se pessoal, quando cada um de nós vivencia uma obra de arte, converte-se em pessoal sem com isto deixar de continuar social.

Quando Vigotski escreveu esse livro, a obra de Marx que citei anteriormente ainda não fora publicada. Seria mero acaso essa grande aproximação entre as concepções contidas nas duas citações?

Absolutamente não. Vigotski talvez não conhecesse esse texto de Marx, mas conhecia outras obras do filósofo alemão, além de conhecer os trabalhos de outros autores no campo do marxismo. O domínio que tinha do método materialista histórico-dialético levou-o a não aceitar o subjetivismo que predominava na análise dos processos psicológicos mais elevados e complexos do ser humano, como é o caso daqueles ligados à criação e à fruição da obra de arte. A mediação social era vista por Vigotski como a própria essência do psiquismo humano.

Na mesma linha de análise, Leontiev argumenta que o "ouvido verbal" e o pensamento lógico não resultam de processos individuais endógenos mas sim da apropriação da linguagem e da lógica objetivamente existentes na sociedade. 


\section{Nessa perspectiva materialista, histórica e dialética das relações existentes entre o mundo humano objetivo e o mundo humano subjetivo, qual é a crítica que o professor faz às teses que predominam atualmente na educação escolar?}

Eu afirmo que, na perspectiva de uma pedagogia marxista, que é a que eu defendo, torna-se totalmente desprovida de sentido a tese escolanovista, reeditada pelo construtivismo, de que, na educação escolar, o processo de aquisição (ou construção) do conhecimento seria mais importante do que o conteúdo do conhecimento adquirido (ou construído).

\section{Mas não é o que defende Piaget em seus escritos?}

Exatamente! Piaget, numa conferência proferida em 1947, intitulada "O desenvolvimento moral do adolescente em dois tipos de sociedade: sociedade primitiva e sociedade 'moderna'", estabeleceu uma nítida oposição entre a transmissão, ao aluno, de conhecimentos existentes, e o oferecimento de condições que permitam a ele construir suas próprias verdades. É interessante transcrever um trecho da referida conferência:

O problema da educação internacional é, portanto, essencialmente o de direcionar o adolescente não para soluções prontas, mas para um método que lhe permita construí-las por conta própria. A esse respeito, existem dois princípios fundamentais e correlacionados dos quais toda educação inspirada pela psicologia não poderia se afastar: 1) que as únicas verdades reais são aquelas construídas livremente e não aquelas recebidas de fora; 2) que o bem moral é essencialmente autônomo e não poderia ser prescrito. Desse duplo ponto de vista, a educação internacional é solidária de toda a educação. Não apenas a compreensão entre os povos que se vê prejudicada pelo ensino de mentiras históricas ou de mentiras sociais. Também a formação humana dos indivíduos é prejudicada quando verdades, que poderiam descobrir sozinhos, lhes são impostas de fora, mesmo que sejam evidentes ou matemáticas: nós os privamos então de um método de pesquisa que lhes teria sido bem mais útil para a vida que o conhecimento correspondente! Prejudica-se igualmente essa formação humana dando aos adolescentes aulas de civismo e de internacionalismo, se estas aulas consomem o tempo que eles teriam podido ocupar descobrindo sozinhos esse civismo ou esse internacionalismo no exercício de uma vida social organizada espontaneamente. Sempre que o discurso substitui a ação efetiva, o progresso da consciência é retardado.

(Piaget, 1998, p.166, grifo do entrevistado) 
Note-se que, nessa passagem aparecem com clareza dois princípios pedagógicos: o de que aquilo que o indivíduo aprende por si mesmo é superior, em termos educativos e sociais, àquilo que ele aprende por meio da transmissão por outras pessoas e o princípio de que o método de construção do conhecimento é mais importante do que o conhecimento já produzido socialmente. Em minhas pesquisas, faço uma crítica às correntes psicológicas e pedagógicas que consideram os processos de aquisição do conhecimento mais importantes do que o próprio conhecimento. $E$ as idéias de Piaget estão incluídas em minha crítica.

\section{O construtivista espanhol Juan Delval também defende de forma explícita que a escola deve preocupar-se menos com o conhecimento científico já existente e voltar-se à formação de uma atitude científica nas crianças, mediante observação dos fenômenos naturais e sociais. Qual é seu posicionamento em relação a essa idéia?}

Primeiramente é importante rever o texto de Delval (1998, p.160) em que ele explicita essa idéia:

...o pensamento científico deve ocupar um papel central no trabalho escolar. Mas o pensamento científico é, principalmente, um método, uma atitude, uma forma de abordar os problemas e não uma série de idéias, de conteúdos ou de resultados aos quais os homens chegaram ao longo da sua história. Não devemos perder de vista que o nosso objetivo é o de ensinar a pensar livremente, criativamente, para dar origem a indivíduos melhores, mais livres e, na medida do possível, mais felizes. Por isso, não tem nenhuma utilidade, se o que queremos é contribuir para o aprimoramento do homem, que as crianças aprendam muita física ou muita história. $\mathrm{O}$ importante é que sejam capazes de refletir sobre o universo físico e sobre o universo social. O que precisam aprender é essa atitude diante das coisas e essa atitude somente será alcançada com a prática, exercitando em sala de aula o pensamento rigoroso e criativo diante de problemas novos.

Poderíamos dizer que o que é preciso aprender é a compreender a natureza da atividade científica, que é, acima de tudo, uma forma de tratar as coisas, de interrogar a realidade, de duvidar das explicações geralmente admitidas $e$ de examinar as conseqüências das nossas conjecturas. Em última análise, é a busca permanente do porquê das coisas e a reconstrução de um sistema que permita organizar o mundo.

Meu questionamento em relação a essa idéia é a de que ela também se apóia em dicotomias, neste caso, entre conteúdo e forma e entre processo e produto. No limite, essa idéia acaba por esvaziar o processo educativo, descaracterizando-o totalmente. Cabe aqui lembrar o que já afirmara Saviani (1989, p. 86-87) em relação à Escola Nova: 
Veja-se o paradoxo em que desemboca a escola nova; a contradição interna que atravessa de ponta a ponta sua proposta pedagógica: de tanto endeusar o processo, de tanto valorizá-lo em si e por si, acabou por transformá-lo em algo místico, uma entidade metafísica, uma abstração esvaziada de conteúdo e sentido.

Em oposição a essa perspectiva escolanovista e construtivista, defendo a construção coletiva de uma pedagogia apoiada na diretriz metodológica sintetizada por Marx na fórmula "a anatomia do homem é a chave da anatomia do macaco". Em meu texto "Sociedade do conhecimento ou sociedade das ilusões? - quatro ensaios crítico-dialéticos em filosofia da educação", de 2003 (p. 39-83), discuto as relações dessa diretriz metodológica com a psicologia de Vigotski e com uma pedagogia marxista.

\section{E que exigências essa pedagogia traz ao educador?}

Tal pedagogia exige a compreensão das contradições que marcam o processo histórico no qual a riqueza material e intelectual humana é construída e ampliada por meio da exploração das classes dominadas (os escravos, os servos e os proletários). Na sociedade capitalista essa contradição entre a riqueza do gênero humano e a pobreza que caracteriza a vida da maioria dos indivíduos chega a seu ponto extremo, tornando-se insuportável. A alienação não atinge apenas a atividade de trabalho em si mesma, a qual é opressiva, desumanizante e sem outro sentido para o trabalhador além daquele dado pela venda de sua força de trabalho, recebendo em troca um salário que possibilita tão somente a reprodução da capacidade de trabalho. Atualmente tende a generalizar-se a situação de grande penúria existente à época de Marx e momentaneamente disfarçada pela curta e localizada existência do Welfare State. A maioria absoluta da humanidade vê-se diante de uma realidade nada alentadora em termos do que serão suas condições de vida no futuro imediato.

Diante da situação de total expropriação da classe trabalhadora de todos os meios de existência - à exceção, unicamente, da própria força de trabalho Marx não adotou a atitude, tão comum atualmente, de defender ações sociais paliativas adaptadas às circunstâncias locais desta ou daquela comunidade, deste ou daquele grupo de "excluídos". Ele defendeu que a única forma possível de superação do grande distanciamento entre a vida dos indivíduos e a riqueza universal do gênero humano seria a apropriação dessa riqueza em sua totalidade pelo conjunto da classe trabalhadora. Em termos da riqueza intelectual, isto é, do conhecimento, a concepção defendida por Marx não dá margem para nenhum tipo de relativismo cultural ou de pedagogia multiculturalista ou, ainda, de desvalorização da ciência à maneira dos intelectuais pós-modernos. Em a Ideologia Alemã (1998, p. 59) ele afirma que 
A libertação de cada indivíduo singular será alcançada na medida em que a história seja totalmente transformada em história mundial. A riqueza real do indivíduo depende inteiramente da riqueza de suas conexões reais. Apenas isso libertará os indivíduos das barreiras nacionais e locais, os trará para a conexão prática com a produção (inclusive a produção intelectual) de todo o mundo e tornará possível a eles a aquisição da capacidade de desfrutar dessa multilateral produção de todo o planeta [as criações do homem].

\section{Trazendo isso para a esfera da educação escolar...}

Se a educação escolar for entendida como formação humana, deverá tomar como referência para a definição dos conteúdos escolares as formas mais desenvolvidas e ricas do conhecimento produzido pela humanidade. Se a educação escolar tiver esta perspectiva, os conteúdos escolares, os métodos de ensino e toda organização do sistema escolar (desde a educação infantil até o ensino superior), deverão voltar-se para a reprodução - nos indivíduos - da riqueza universal do gênero humano, para o estabelecimento de múltiplas e cada vez mais desenvolvidas relações entre essa riqueza e a formação dos indivíduos.

\section{Focalizando a educação brasileira, que reflexões o professor nos} traz em termos dessa formação humana?

Quão longe estamos dessa perspectiva... Quão pobre mostra-se nossa educação escolar se a avaliarmos tomando por referência a riqueza universal do gênero humano, ao invés aceitarmos os parâmetros dados pelo cotidiano alienado ou pelas demandas de um mercado de trabalho cada vez mais decidido a exigir do trabalhador a entrega irrestrita de suas energias físicas e psíquicas, sua saúde física e mental. Segundo a retórica educacional atualmente dominante, não há mais conteúdos a serem ensinados, pois todo saber tornou-se relativo... A ciência passou a ser considerada uma ilusão iluminista ou, pior ainda, o conhecimento objetivo teria deixado de existir, assim como não existiria uma cultura humana, mas infinitas "culturas locais". E mais: mesmo que o conhecimento existisse, ele não deveria ser ensinado, pois conhecimento não se transmite, é construído num processo, cujo lema central é: aprender a aprender ou, segundo os famosos quatro pilares da educação segundo a Unesco: "aprender a conhecer, aprender a fazer, aprender a ser e aprender a viver juntos". Coerentemente com essa visão, defende-se que o professor também deve aprender a aprender, também deve construir seu conhecimento e os cursos de licenciatura são todos reformulados na lógica da pedagogia do professor reflexivo e da pedagogia das competências, a mesma que forneceu os argumentos necessários à precarização do ensino médio destinado aos filhos da classe trabalhadora, submetendo-os a uma formação 
profissionalizante centrada no conceito de empregabilidade, que significa nada mais do que a formação de um trabalhador disposto a se adaptar a qualquer tipo de trabalho. O discurso da qualificação que tenta justificar o princípio da empregabilidade é um disfarce para um processo de diminuição drástica do papel dos conteúdos escolares clássicos na formação dos jovens no ensino médio.

\section{E nos outros níveis, a situação é diferente?}

No campo do ensino fundamental as coisas não são melhores. As pedagogias burguesas supostamente progressistas, tais como a Escola Nova, o Construtivismo, a Pedagogia dos Projetos etc., que encantam boa parte da esquerda educacional, tornaram-se pedagogias oficiais e produziram uma escola repleta de atividades e vazia de conteúdos. Soma-se a isso a disseminação, entre o professorado, de um conjunto de preconceitos em relação às crianças, aos adolescentes e aos jovens da classe trabalhadora, tais como os famosos problemas de aprendizagem, o suposto desinteresse pela escola e pelo estudo, o alegado descaso da família etc... O resultado é a produção de analfabetismo e ignorância por parte da instituição que deveria difundir a cultura escrita para toda a sociedade. Há quem justifique toda essa situação afirmando que o papel social da escola, se um dia foi o de transmissão do conhecimento, hoje não mais o seria. Hoje a escola teria por papel desenvolver a sociabilidade, entendida como o desenvolvimento da capacidade de convivência mutuamente tolerante, a qual implica, é claro, a participação "construtiva" na manutenção da ordem social necessária à reprodução do capital.

\section{Voltando a Marx... o que uma pedagogia marxista deve levar em conta ao ser formulada?}

Nos “Grundrisse", Marx (1993, p.487-488) afirmou que a riqueza produzida na sociedade capitalista deve ser despida de sua forma burguesa e então essa riqueza se revela como: 1) a universalidade das necessidades, capacidades, prazeres, forças produtivas etc. dos indivíduos; 2) o pleno desenvolvimento do domínio humano das forças da natureza, incluindo-se a própria natureza humana; 3 ) a total explicitação das potencialidades criativas humanas sem nenhum outro pressuposto que não seja o prévio desenvolvimento histórico; 4) a transformação do desenvolvimento do gênero humano e do indivíduo em um fim em si mesmo, sem nenhum padrão de medida pré-estabelecido; 5) a transformação da vida do indivíduo em um processo no qual ele produz a si mesmo como uma totalidade de forças humanas. Marx não descreveu dessa forma a riqueza humana com a finalidade de expressar sua esperança numa utopia. O que ele fez foi descrever as possibilidades reais criadas pela própria sociedade burguesa. A construção de uma pedagogia marxista deve ter essas possibilidades como referência para situar-se no campo mais amplo de uma luta mundial pela superação da sociedade capitalista, a qual vem produzindo a barbárie em escala crescente. 
Uma pedagogia superior ao capitalismo terá que incorporar tudo aquilo que, tendo sido produzido na sociedade capitalista, possa contribuir para o desenvolvimento do gênero humano, para o enriquecimento material e intelectual da vida de todos os seres humanos. É por essa razão que adoto a atitude de rejeição integral das proposições pós-modernas no campo educacional. Minha recusa do pensamento pós-moderno não decorre do fato dele ser um produto cultural da sociedade burguesa, mas por se tratar de uma ideologia que, ao invés de valorizar aquilo que de humanizante a sociedade burguesa tenha produzido, entrega-se de corpo e alma à celebração do irracionalismo, do ceticismo e do cinismo.

\section{Trata-se de uma posição radical...}

Com toda a certeza! E minha radical rejeição ao pensamento pós-moderno visa, entre outras coisas, defender uma abordagem marxista que supere os limites do Iluminismo sem negar o caráter emancipatório do conhecimento $e$ da razão; que supere os limites da democracia burguesa sem negar a necessidade da política; que supere os limites da ciência posta a serviço do capital sem, entretanto, negar o caráter indispensável da ciência para o desenvolvimento humano; que supere a concepção burguesa de progresso social sem negar a possibilidade de fazer a sociedade progredir na direção de formas mais evoluídas de existência humana. No campo educacional, tudo isso se traduz no que defendo: uma pedagogia marxista que supere a educação escolar em suas formas burguesas sem negar a importância da transmissão, pela escola, dos conhecimentos mais desenvolvidos que já tenham sido produzidos pela humanidade. Isso não poderá ser feito sem a contribuição de uma psicologia que ajude os educadores a dominarem a psicologia humana contida na riqueza intelectual objetivamente existente na sociedade.

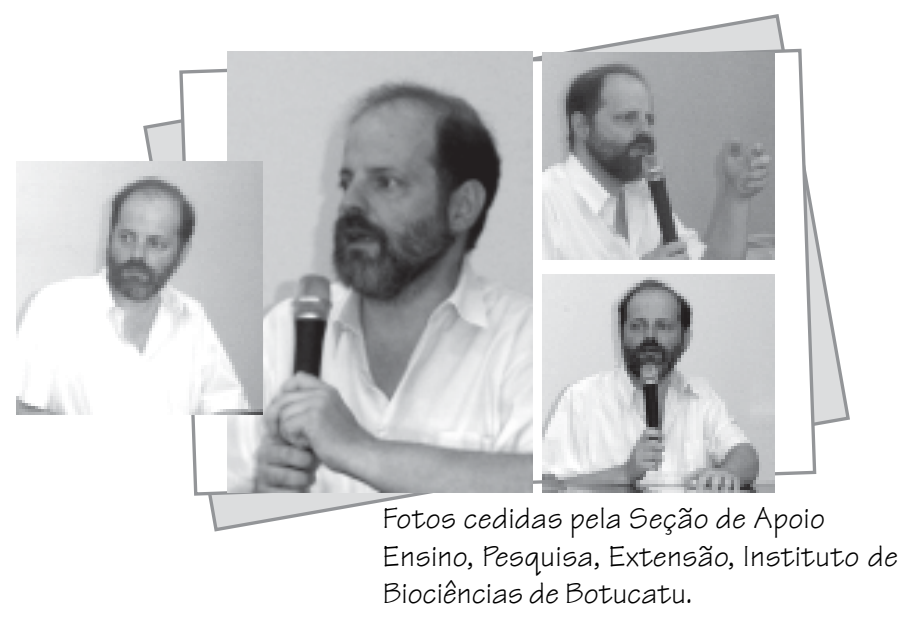

PALAVRAS-CHAVE: Psicologia. Marxismo. Pedagogia. Conhecimento. Construtivismo. KEY WORDS: Psychology. Marxism. Pedagogy. Knowledge. Construtivism. PALABRAS CLAVE: Psicología. Marxismo. Pedagogia. Conocimiento. Construtivismo.

Contato: Rodovia Araraquara-Jaú, km 1, Bairro dos Machado - Araraquara, SP 14.800-901 <newton.duarte@uol.com.br> 